\title{
Predictors of postconcussion syndrome in collegiate student-athletes
}

\author{
Scott L. Zuckerman, MD, ${ }^{1,2}$ Aaron M. Yengo-Kahn, BS, ${ }^{1}$ Thomas A. Buckley, EdD, ${ }^{3}$ \\ Gary S. Solomon, PhD, ${ }^{1,2}$ Allen K. Sills, MD, ${ }^{1,2}$ and Zachary Y. Kerr, PhD, MPH ${ }^{4}$
}

${ }^{1}$ Vanderbilt Sports Concussion Center and ${ }^{2}$ Department of Neurological Surgery, Vanderbilt University School of Medicine, Nashville, Tennessee; ${ }^{3}$ Department of Kinesiology and Applied Physiology, University of Delaware, Newark; and ${ }^{4}$ Datalys Center for Sports Injury Research and Prevention, Indianapolis, Indiana

OBJECTIVE Sport-related concussion (SRC) has emerged as a public health problem, especially among studentathletes. Whereas most concussions resolve by 2 weeks, a minority of patients experience postconcussion syndrome (PCS), in which symptoms persist for months. The objective of this study was to elucidate factors predictive of PCS among a sample of National Collegiate Athletic Association (NCAA) student-athletes in the academic years 2009-2010 to $2014-2015$.

METHODS The SRC data originated from the NCAA Injury Surveillance Program (ISP) in the 2009-2010 to 2014-2015 academic seasons. The NCAA ISP is a prospective database made up of a convenience sample of schools across all divisions. All SRCs are reported by certified athletic trainers. The PCS group consisted of concussed student-athletes with concussion-related symptoms that lasted $\geq 4$ weeks. The non-PCS group consisted of concussed student-athletes with symptom resolution in $\leq 2$ weeks. Those with symptoms that resolved in the intermediate area of 2-4 weeks were excluded. Odds ratios (ORs) were estimated using logistic regression.

RESULTS During the 2009-2010 to 2014-2015 seasons, 1507 NCAA student-athletes sustained an SRC, 112 (7.4\%) of whom developed PCS (i.e., concussion-related symptoms that lasted $\geq 4$ weeks). Men's ice hockey contributed the largest proportion of concussions to the PCS group (28.6\%), whereas men's football contributed the largest proportion of concussions in the non-PCS group (38.6\%). In multivariate analysis, recurrent concussion was associated with increased odds of PCS (OR 2.08, 95\% Cl 1.28-3.36). Concussion symptoms that were also associated with increased odds of PCS included retrograde amnesia (OR 2.75, 95\% Cl 1.34-5.64), difficulty concentrating (OR 2.35, 95\% Cl 1.23-4.50), sensitivity to light (OR 1.97, 95\% Cl 1.09-3.57), and insomnia (OR 2.19, 95\% Cl 1.30-3.68). Contact level, sex, and loss of consciousness were not associated with PCS.

CONCLUSIONS Postconcussion syndrome represents one of the most impactful sequelae of SRC. In this study of exclusively collegiate student-athletes, the authors found that recurrent concussions and various concussion-related symptoms were associated with PCS. The identification of initial risk factors for the development of PCS may assist sports medicine clinicians in providing timely interventions and treatments to prevent morbidity and shorten recovery time after SRC.

http://thejns.org/doi/abs/10.3171/2016.1.FOCUS15593

KEY WORDS sport-related concussion; traumatic brain injury; collegiate athletics; NCAA; postconcussion syndrome

$\mathrm{S}$ PORT-RELATED concussion (SRC), which affects athletes of all ages and levels of competition, has taken hold of the national spotlight. An estimated 1.6-3.8 million SRCs occur each year in the United States, but this may be an underestimation because of those who fail to seek medical care..$^{11,20,22,29}$ Concussion in college athletics has been studied extensively. ${ }^{11,52}$ In 2010, the National
Collegiate Athletic Association (NCAA) implemented a 4-pronged concussion policy that included mandatory education, immediate removal from play, no same-day return to play, and a requirement for clearance by a medical professional. ${ }^{5,34}$ Recent reports have summarized SRC epidemiology at the collegiate level, ${ }^{48,52}$ yet concussion remains an evolving injury in need of study.

ABBREVIATIONS AT = athletic trainer; ISP = Injury Surveillance Program; LOC = loss of consciousness; NCAA = National Collegiate Athletic Association; PCS = postconcussion syndrome; $\mathrm{SRC}=$ sport-related concussion.

SUBMITTED December 1, 2015. ACCEPTED January 28, 2016.

INCLUDE WHEN CITING DOI: 10.3171/2016.1.FOCUS15593. 
Whereas $85 \%-90 \%$ of athletes with SRC are asymptomatic by $10-14$ days after injury, ${ }^{24,26,29}$ a subset of them experience unremitting symptoms, referred to as postconcussion syndrome (PCS). ${ }^{21,43}$ This syndrome has many definitions. The International Statistical Classification of Diseases and Related Health Problems, 10th Revision, defines PCS as 3 or more symptoms persisting for greater than 4 weeks. Similarly, the Diagnostic and Statistical Manual of Mental Disorders, 4th Edition (DSM-IV), defines it as 3 or more symptoms but persisting for a minimum of 3 months, ${ }^{2}$ and the DSM-V does not include the diagnosis. ${ }^{3}$ In a survey of more than 500 physicians, the majority of them diagnosed PCS in patients who endorsed at least 1 symptom for a minimum of 4 weeks. ${ }^{42}$

Many reports have outlined risk factors for PCS, $, 813,15$, $17,23,25,28,40,45,50,51$ but few studies have been performed in an exclusively sports population. . $^{12,26,30,31,33}$ Documented risk factors for PCS in athletes include initial symptom score, ${ }^{26,31}$ loss of consciousness (LOC), ${ }^{23}$ amnesia, ${ }^{26}$ and female sex, ${ }^{28,50}$ although considerable debate has surrounded each factor. ${ }^{45}$ Whereas individual factors such as concussion history and learning disability have been well studied, few studies have aimed to elucidate sport-specific factors that may predispose athletes to PCS. If predictive factors can be identified in a homogeneous population, symptoms can be managed more aggressively in an effort to minimize symptom duration and improve quality of life. Compared with the general population, collegiate student-athletes represent a viable starting point because they have access to a full cohort of certified athletic trainers (ATs) and physicians with limited insurance restrictions.

Given the potentially debilitating effects of prolonged postconcussion symptoms in collegiate student-athletes, we sought to further investigate risk factors for PCS after SRC. The objective of this study was to elucidate factors predictive of PCS among an exclusive group of collegiate student-athletes who sustained an SRC in the 2009-2010 to 2014-2015 academic years.

\section{Methods}

The NCAA Injury Surveillance Program (ISP) is a prospective surveillance program managed by the Datalys Center for Sports Injury Research and Prevention, an independent nonprofit research organization. Data from the 2009-2010 to 2014-2015 academic years were obtained from the NCAA ISP. This study was approved by the NCAA Research Review Board.

\section{Data Collection}

The methodology of the NCAA ISP during the 20092010 to 2014-2015 academic years was described previously. ${ }^{16}$ The ISP collects student-athlete data from a convenience sample of NCAA varsity teams across 25 sports among all 3 divisions. Individual school sponsorship varies by sport and year; for example, during the 20092010 to 2014-2015 seasons, 57 men's football programs provided 153 team-seasons, and of these programs, 29 were Division I (76 team-seasons), 9 were Division II (28 team-seasons), and 19 were Division III (49 team-seasons).
Similar trends, summarized in a separate paper, were seen across other sports. ${ }^{16}$

Athletic trainers recorded injury data during all schoolsanctioned practices, workouts, and competitions. In the event of an injury, or, in this case, an SRC, the AT reported the injury in real time through an electronic health record program used by the team medical staff throughout the academic year. The ISP captured other sports-related adverse health events such as illness, heat-related conditions, and general medical conditions. Although team workouts were captured, individual weight-lifting and conditioning sessions were excluded.

For each SRC, the AT completed a detailed event report on the injury or condition (e.g., body part, diagnosis) and the circumstances (e.g., activity, mechanism, recurrence, event type [i.e., competition or practice]). Recurrent concussion was determined in student-athletes who had more than 1 concussion reported during their team's participation in the ISP or who had their most recent concussion noted by ATs as being recurrent. In other words, a concussion was classified as recurrent if the athlete had suffered a previous concussion during his or her collegiate athletic career. Thus, for each concussed athlete used in the data analysis, only the most recent concussion reported in the ISP was examined. Furthermore, the total duration of symptoms was collected longitudinally. The ATs updated the electronic medical record as needed to update injury information, such as time lost and time to symptom resolution.

Common data elements, including injury, exposure, and longitudinal information, were stripped of any personally identifiable information and retained only relevant variables..$^{16}$ The frequency of export or submission of data varied slightly among vendors providing health information to each team's medical staff. Because the program removed any identifiers, ATs were subsequently allowed to document injuries as part of their daily clinical practice and did not have to complete separate reports specifically for the ISP. Furthermore, all electronic health record information was subjected to a data-validation process for certification. Once entered, exported data were put through an automated verification process to check for consistency. These data were reviewed and flagged for invalid values. Any discrepancies or invalid values were resolved mutually by the AT and data quality assurance staff. All data that passed the verification process were then placed into the aggregate data sets.

It should be noted that, although some studies that evaluated PCS included individual and family medical histories, ${ }^{25,32-35,50}$ the sport-focused nature of the ISP prevented any in-depth medical history from being collected. However, the ISP allowed us to collect sport-specific information surrounding the inciting injury.

\section{Definitions}

A reportable injury in the ISP was defined as an injury that occurred as a result of participation in an organized intercollegiate practice/competition and required attention from an AT or physician. Multiple injuries could be included as a result of 1 injury event. Although the ATs were encouraged to follow the international definition of con- 
cussion provided by the Consensus Statement on Concussion in Sport, ${ }^{27}$ a predetermined definition of concussion was not provided. We relied on the medical expertise of the ATs providing data for the NCAA ISP.

Cases were defined as those that involved a studentathlete who experienced 1 or more symptom related to an SRC for greater than 4 weeks, as has been characterized in previous reports of PCS. ${ }^{6,7,25,31,47}$ Controls were defined as student-athletes with symptom resolution at $\leq 2$ weeks. Any student-athlete with symptom resolution in the intermediate area of $>2$ weeks but $<4$ weeks was excluded from our analysis to sharply demarcate the control and PCS groups, which is similar to the methodology used in previous studies. ${ }^{32,33}$ This exclusionary criterion was imposed to sharply delineate the continuum of typical to prolonged trajectory, because the primary objective of this study was not epidemiological or prevalence based but, rather, to elucidate factors associated with PCS. The remaining exclusion criteria included student-athletes with missing concussion history data or symptomatology information. After imposing these exclusionary measures, all remaining concussed studentathletes were included in the analysis.

The student-athletes were drawn from all 25 collegiate sports, recently reported in a pair of NCAA SRC epidemiology studies ${ }^{48,52}$ All predictive factors are outlined in Table 1. Contact level was determined by using a preexisting classification system. ${ }^{41,44}$ Helmet status was determined as previously described, and those sports played partly with helmets were included in the helmeted group, except when only the goalie was helmeted.$^{53}$ Recurrent SRC was defined as more than 1 SRC suffered during the studentathlete's participation in the ISP. A comprehensive list of 17 symptoms was used.

\section{Statistical Analysis}

Data were analyzed using SAS-Enterprise Guide soft- ware version 4.3 (SAS Institute Inc.). Unlike other studies that used the ISP, ${ }^{48,52}$ the unit of analysis was not concussions but each concussed person, because the primary purpose of this study was to assess factors associated with prolonged SRC symptomatology and not SRC per se. Thus, for each concussed individual used in the data analysis, only the most recent concussion reported in the ISP was examined.

Demographic data were analyzed to describe studentathletes with PCS. Continuous variables are presented as means and standard deviations. Categorical variables are presented as percentages of the total population. Odds ratios and 95\% CIs were estimated using logistic regression. Simple univariate logistic regressions were used to predict the odds of PCS. The variables assessed were sex, contact level, helmet status, recurrent concussion, number of symptoms, and prevalence of each of 17 symptoms. Number of symptoms was treated as a continuous variable (i.e., the beta for number of symptoms represents the increase in log odds of PCS for each additional symptom reported). All variables for which univariate analyses yielded a $p$ value of $<0.010$ were included in a multiple logistic regression model. For the multivariate analysis, all ORs with a 95\% CI that did not include 1.0 were considered statistically significant.

\section{Results \\ Demographics}

During the 2009-2010 to 2014-2015 seasons, 1866 concussed NCAA student-athletes were reported in the NCAA ISP, and 1507 met the criteria for inclusion (Fig. 1). Student-athlete characteristics are provided in Table 2. One hundred-twelve (7.4\%) student-athletes developed PCS. Men's ice hockey was the sport played by the majority of athletes in the PCS group (28.6\%), whereas men's football was the most common sport played by those in the

TABLE 1. Variables considered for the model predicting prevalence of PCS among concussed student-athletes in NCAA sports

\begin{tabular}{|c|c|}
\hline Variable & Values \\
\hline Sex & Men [M], women [W] \\
\hline \multirow[t]{3}{*}{ Contact level } & Collision (football [M], ice hockey [M], wrestling [M]) \\
\hline & High contact (soccer [M/W], basketball [M/W], lacrosse [M], ice hockey [W]) \\
\hline & $\begin{array}{l}\text { Low/noncontact (baseball [M], softball [W], lacrosse [W], volleyball [W], gymnastics [W], field hockey } \\
{[\mathrm{W}] \text {, cross-country/track [M/W], tennis [M/W], swimming/diving [M/W]) }}\end{array}$ \\
\hline \multirow[t]{2}{*}{ Helmet status } & Helmeted (football [M], ice hockey [M/W], lacrosse [M], wrestling [M], baseball [M], ${ }^{*}$ softball [W] ${ }^{*}$ ) \\
\hline & $\begin{array}{l}\text { Unhelmeted (basketball [M/W], soccer [M/W], lacrosse [W], volleyball [W], gymnastics [W], field hockey } \\
{[\mathrm{W}], \dagger \text { cross-country/track [M/W], tennis [M/W], swimming/diving [M/W]) }}\end{array}$ \\
\hline Recurrent concussion & Yes, no \\
\hline Symptom prevalence & $\begin{array}{l}\text { Yes or no for } 17 \text { symptoms (posttraumatic amnesia, retrograde amnesia, difficulty concentrating, disori- } \\
\text { entation, dizziness, headache, excess excitability, excess irritability, LOC, nausea/vomiting, tinnitus, } \\
\text { loss of balance, visual disturbance, sensitivity to light, sensitivity to noise, insomnia, and excess } \\
\text { drowsiness) }\end{array}$ \\
\hline No. of symptoms & Range of $1-17$ \\
\hline \multicolumn{2}{|c|}{$\begin{array}{l}\text { * Because baseball and softball are played partly while wearing helmets, student-athletes who played this sport were included in the helmeted } \\
\text { group. } \\
\dagger \text { There was } 1 \text { concussion sustained by a goalie in field hockey. Because goalies in this sport wear helmets, this case was included in the } \\
\text { helmeted group. }\end{array}$} \\
\hline
\end{tabular}




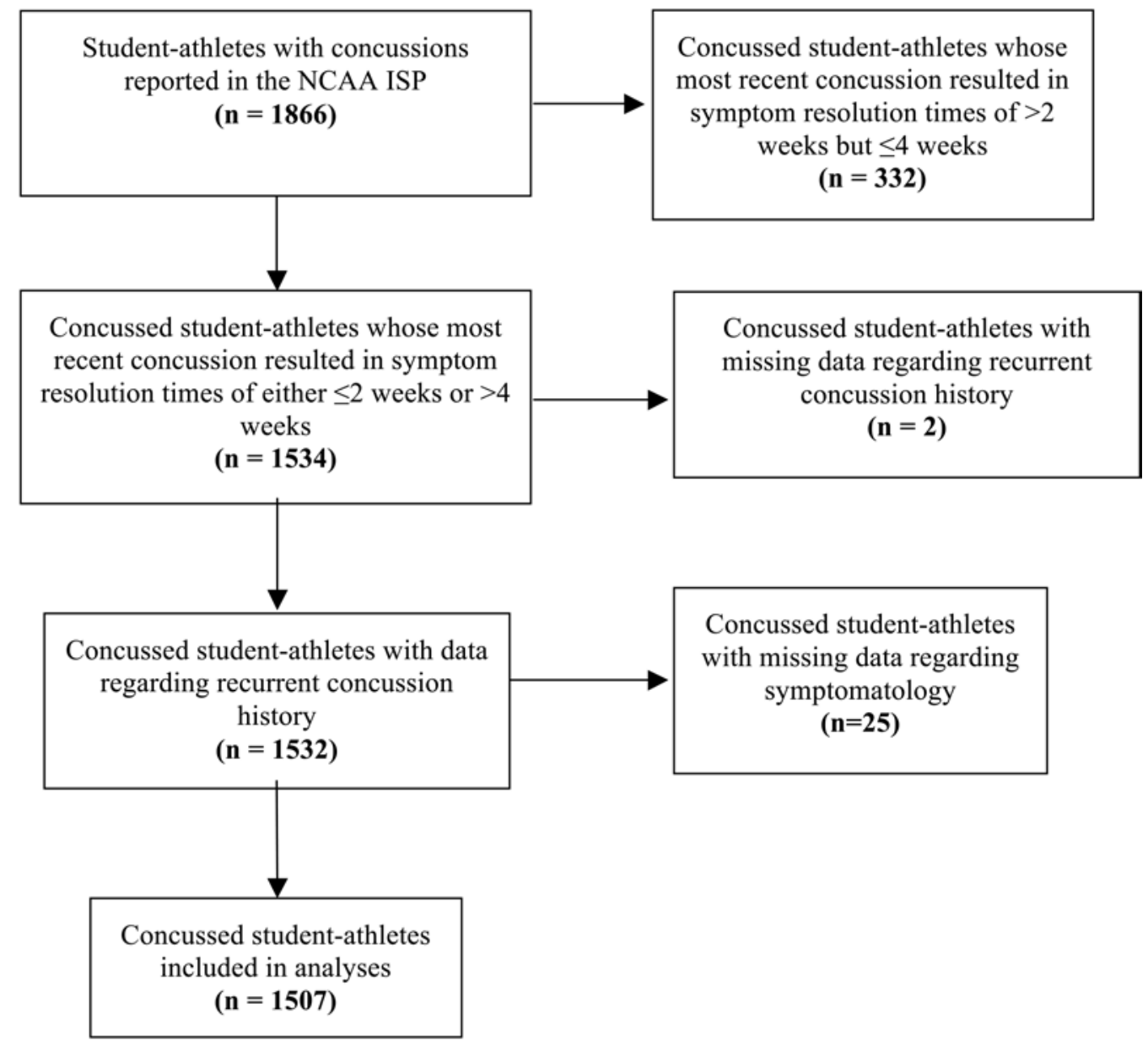

FIG. 1. Flow chart of final cohort.

non-PCS group (38.6\%). The PCS and non-PCS groups did not differ in regards to sex, contact level, or helmet status. However, compared with the non-PCS group, the PCS group had a greater proportion of student-athletes with recurrent concussion $(\mathrm{p}<0.001)$ and a higher average number of symptoms $(\mathrm{p}<0.001)$.

\section{Univariate Analysis}

The odds of PCS increased among student-athletes with recurrent concussion (OR 2.22, 95\% CI 1.41-3.50; Table $3)$. The odds of PCS also increased among student-athletes who played helmeted sports (OR 1.48, 95\% CI 0.95-2.30). In terms of symptoms, the odds of PCS increased $26 \%$ for each additional symptom reported (OR 1.26, 95\% CI 1.181.34). In addition, the odds of PCS were higher among those who reported the following concussion symptoms than those who did not report them: posttraumatic amnesia, retrograde amnesia, difficulty concentrating, dizziness, excess irritability, nausea/vomiting, loss of balance, visual disturbance, sensitivity to light, sensitivity to noise, insomnia, and excess drowsiness. In addition, the univariate analysis for helmet status yielded a $\mathrm{p}$ value of $<0.08$.

\section{Multivariate Analysis}

A multivariate model was constructed by using all the variables for which the OR in univariate analyses yielded a $p$ value of $<0.10$ (Table 4). Controlling for other variables, recurrent concussion was associated with increased odds of PCS (OR 2.08, 95\% CI 1.28-3.36). Concussion symptoms also associated with increased odds of PCS, when controlling for other variables, included retrograde amnesia (OR 2.75, 95\% CI 1.34-5.64), difficulty concentrating (OR 2.35, 95\% CI 1.23-4.50), sensitivity to light (OR $1.97,95 \%$ CI 1.09-3.57), and insomnia (OR 2.19, $95 \%$ CI $1.30-3.68)$.

\section{Discussion}

Our findings originate from surveillance data that examined concussions sustained in 25 NCAA sports throughout the 2009-2010 to 2014-2015 seasons. Several variables were found to be associated with the odds of PCS, including recurrent concussion, retrograde amnesia, difficulty concentrating, light sensitivity, and insomnia. Sex, helmet status, contact level, and LOC were not associated with PCS. Our results highlight the importance of identifying potential risk factors before and at the onset of concussion.

As in previous research, ${ }^{33,39}$ recurrent concussion was associated with protracted recovery. Morgan et al..$^{33}$ studied a pediatric sports-related population by using multivariate analysis and found that history of concussion was 
TABLE 2. Characteristics of concussed student-athletes in NCAA sports

\begin{tabular}{|c|c|c|c|c|}
\hline Characteristic & Total & PCS & No PCS & p Value* \\
\hline Sex (no. [\%]) & & & & 0.14 \\
\hline Male & $1037(68.8)$ & $70(62.5)$ & $967(69.3)$ & \\
\hline Female & $470(31.2)$ & $42(37.5)$ & $428(30.7)$ & \\
\hline Sport (no. [\%]) & & & & NA \\
\hline Men's football & $563(37.4)$ & $25(22.3)$ & $538(38.6)$ & \\
\hline Men's ice hockey & $200(13.3)$ & $32(28.6)$ & $168(12)$ & \\
\hline Women's soccer & $121(8)$ & $8(7.1)$ & $113(8.1)$ & \\
\hline Women's basketball & $86(5.7)$ & $6(5.4)$ & $80(5.7)$ & \\
\hline Men's basketball & $76(5)$ & $1(0.9)$ & $75(5.4)$ & \\
\hline Men's wrestling & $72(4.8)$ & $5(4.5)$ & $67(4.8)$ & \\
\hline Women's ice hockey & $72(4.8)$ & $15(13.4)$ & $57(4.1)$ & \\
\hline Women's volleyball & $56(3.7)$ & $1(0.9)$ & $55(3.9)$ & \\
\hline Men's soccer & $52(3.5)$ & $2(1.8)$ & $50(3.6)$ & \\
\hline Women's lacrosse & $50(3.3)$ & $3(2.7)$ & $47(3.4)$ & \\
\hline Men's lacrosse & $48(3.2)$ & $3(2.7)$ & $45(3.2)$ & \\
\hline Women's softball & $47(3.1)$ & $2(1.8)$ & $45(3.2)$ & \\
\hline Men's baseball & $15(1)$ & $2(1.8)$ & $13(0.9)$ & \\
\hline Women's field hockey & $14(0.9)$ & $2(1.8)$ & $12(0.9)$ & \\
\hline Women's gymnastics & $13(0.9)$ & $4(3.6)$ & $9(0.6)$ & \\
\hline Men's swimming \& diving & $7(0.5)$ & 0 & $7(0.5)$ & \\
\hline Men's track \& field & $4(0.3)$ & 0 & $4(0.3)$ & \\
\hline Women's swimming \& diving & $4(0.3)$ & $1(0.9)$ & $3(0.2)$ & \\
\hline Women's track \& field & $4(0.3)$ & 0 & $4(0.3)$ & \\
\hline Women's tennis & $2(0.1)$ & 0 & $2(0.1)$ & \\
\hline Women's cross-country & $1(0.1)$ & 0 & $1(0.1)$ & \\
\hline Contact level (no. [\%]) & & & & 0.93 \\
\hline Collision & $835(55.4)$ & $62(55.4)$ & $773(55.4)$ & \\
\hline High contact & $455(30.2)$ & $35(31.3)$ & $420(30.1)$ & \\
\hline Low/noncontact & $217(14.4)$ & $15(13.4)$ & $202(14.5)$ & \\
\hline Helmet status (no. [\%]) & & & & 0.08 \\
\hline Helmeted & $1018(67.6)$ & $84(75.0)$ & $934(67.0)$ & \\
\hline Unhelmeted & $489(32.4)$ & $28(25.0)$ & $461(33.0)$ & \\
\hline Recurrent concussion (no. [\%]) & & & & $<0.001$ \\
\hline Yes & $210(13.9)$ & $28(25.0)$ & $182(13.0)$ & \\
\hline No & $1297(86.1)$ & $84(75.0)$ & $1213(87.0)$ & \\
\hline No. of symptoms (mean [SD]) & $5.4(2.8)$ & $7.2(3.2)$ & $5.2(2.7)$ & $<0.001$ \\
\hline Total (no. [\%]) & $1507(100.0)$ & $112(100.0)$ & $1395(100.0)$ & \\
\hline
\end{tabular}

positively associated with PCS. Concussion history has been associated with PCS in other studies as well..$^{39}$ These findings highlight the need for those working with student-athletes to be acutely aware of previous concussions, although they may be difficult to elicit on history. Once an athlete has suffered numerous SRCs, each with an expanded recovery time, it has been our anecdotal experience that the student-athlete may be less likely to return to sport as willingly as after previous injuries, especially if there has been a negative academic impact.

Alongside recurrent concussions, specific concussion- related symptoms were also associated with PCS, including retrograde amnesia, difficulty with concentration, insomnia, and sensitivity to light. Retrograde amnesia is defined as the inability to retain information from events that occurred before onset of the cerebral pathology. ${ }^{23,37}$ Although studies in non-sports-related populations have shown no association with PCS, ${ }^{17,23}$ McCrea et al. ${ }^{26}$ found posttraumatic amnesia (similar but different from retrograde amnesia) to be associated with longer symptom recovery; however, their groups were dichotomized at greater than 7 days, a time frame inconsistent with the most standard 
TABLE 3. Univariate analyses predicting odds of PCS in concussed student-athletes in NCAA sports

\begin{tabular}{|c|c|c|c|c|}
\hline Variable & Value & PCS (no./total [\%])* & OR $(95 \% \mathrm{Cl}) \dagger$ & p Value \\
\hline \multirow[t]{2}{*}{ Sex } & Male & $70 / 1037(6.7)$ & $0.74(0.49-1.10)$ & 0.14 \\
\hline & Female & $42 / 470(8.9)$ & 1.0 & \\
\hline \multirow[t]{3}{*}{ Contact level } & Collision & $62 / 835(7.4)$ & $1.08(0.60-1.93)$ & 0.80 \\
\hline & High contact & $35 / 455(7.7)$ & $1.12(0.60-2.10)$ & 0.72 \\
\hline & Low/noncontact & $15 / 217(6.9)$ & 1.0 & \\
\hline \multirow[t]{2}{*}{ Helmet status } & Helmeted & $84 / 1018(8.3)$ & $1.48(0.95-2.30)$ & 0.08 \\
\hline & Unhelmeted & $28 / 489(5.7)$ & 1.0 & \\
\hline \multirow[t]{2}{*}{ Recurrent concussion } & Yes & $28 / 210(13.3)$ & $2.22(1.41-3.50) \dagger$ & $<0.001$ \\
\hline & No & $84 / 1297(6.5)$ & 1.0 & \\
\hline No. of symptoms & (1-unit increase) & & $1.26(1.18-1.34) \dagger$ & $<0.001$ \\
\hline \multicolumn{5}{|l|}{ Symptom prevalence } \\
\hline \multirow[t]{2}{*}{ Posttraumatic amnesia } & Yes & 22/195 (11.3) & $1.73(1.06-2.83) \dagger$ & 0.03 \\
\hline & No & $90 / 1312(6.9)$ & 1.0 & \\
\hline \multirow[t]{2}{*}{ Retrograde amnesia } & Yes & $20 / 132(15.2)$ & $2.49(1.48-4.19) \dagger$ & $<0.001$ \\
\hline & No & $92 / 1375(6.7)$ & 1.0 & \\
\hline \multirow[t]{2}{*}{ Difficulty concentrating } & Yes & $92 / 898(10.2)$ & $3.36(2.05-5.52) \dagger$ & $<0.001$ \\
\hline & No & $20 / 609(3.3)$ & 1.0 & \\
\hline \multirow[t]{2}{*}{ Disorientation } & Yes & $40 / 492(8.1)$ & $1.15(0.78-1.73)$ & 0.47 \\
\hline & No & $72 / 1015(7.1)$ & 1.0 & \\
\hline \multirow[t]{2}{*}{ Dizziness } & Yes & $88 / 1037(8.5)$ & $1.72(1.08-2.74) \dagger$ & 0.02 \\
\hline & No & $24 / 470$ (5.1) & 1.0 & \\
\hline \multirow[t]{2}{*}{ Headache } & Yes & $109 / 1415(7.7)$ & $2.48(0.77-7.95)$ & 0.13 \\
\hline & No & $3 / 92(3.3)$ & 1.0 & \\
\hline \multirow[t]{2}{*}{ Excess excitability } & Yes & $6 / 60(10.0)$ & $1.41(0.59-3.34)$ & 0.44 \\
\hline & No & $106 / 1447(7.3)$ & 1.0 & \\
\hline \multirow[t]{2}{*}{ Excess irritability } & Yes & $24 / 225(10.7)$ & $1.62(1.01-2.61) \dagger$ & 0.05 \\
\hline & No & $88 / 1282(6.9)$ & 1.0 & \\
\hline \multirow[t]{2}{*}{ LOC } & Yes & $8 / 79(10.1)$ & $1.43(0.67-3.06)$ & 0.35 \\
\hline & No & $104 / 1428(7.3)$ & 1.0 & \\
\hline \multirow[t]{2}{*}{ Nausea/vomiting } & Yes & $47 / 465(10.1)$ & $1.69(1.14-2.50) \dagger$ & 0.009 \\
\hline & No & $65 / 1042(6.2)$ & 1.0 & \\
\hline \multirow[t]{2}{*}{ Tinnitus } & Yes & $12 / 118(10.2)$ & $1.46(0.78-2.74)$ & 0.24 \\
\hline & No & $100 / 1389(7.2)$ & 1.0 & \\
\hline \multirow[t]{2}{*}{ Loss of balance } & Yes & $53 / 552(9.6)$ & $1.61(1.10-2.37) \dagger$ & 0.02 \\
\hline & No & $59 / 955(6.2)$ & 1.0 & \\
\hline \multirow[t]{2}{*}{ Visual disturbance } & Yes & $46 / 440(10.5)$ & $1.77(1.19-2.63) \dagger$ & 0.005 \\
\hline & No & $66 / 1067(6.2)$ & 1.0 & \\
\hline \multirow[t]{2}{*}{ Sensitivity to light } & Yes & $81 / 755(10.7)$ & $2.80(1.82-4.28) \dagger$ & $<0.001$ \\
\hline & No & $31 / 752(4.1)$ & 1.0 & \\
\hline \multirow[t]{2}{*}{ Sensitivity to noise } & Yes & $60 / 472(12.7)$ & $2.75(1.87-4.06) \dagger$ & $<0.001$ \\
\hline & No & $52 / 1035(5.0)$ & 1.0 & \\
\hline \multirow[t]{2}{*}{ Insomnia } & Yes & 49/332 (14.8) & $3.06(2.06-4.54) \dagger$ & $<0.001$ \\
\hline & No & $63 / 1175(5.4)$ & 1.0 & \\
\hline \multirow[t]{2}{*}{ Excess drowsiness } & Yes & $51 / 433(11.8)$ & $2.22(1.50-3.27) \dagger$ & $<0.001$ \\
\hline & No & $61 / 1074(5.7)$ & 1.0 & \\
\hline
\end{tabular}

* Of note - denominators added are raw totals in each category

$\dagger$ Statistically significant. 
TABLE 4. Multivariate analyses predicting odds of PCS in concussed student-athletes in NCAA sports

\begin{tabular}{|c|c|c|c|}
\hline Variable & Value & OR $(95 \% \mathrm{Cl})$ & $p$ Value \\
\hline \multirow[t]{2}{*}{ Helmet status } & Helmeted & $1.43(0.90-2.29)$ & 0.13 \\
\hline & Unhelmeted & 1.0 & \\
\hline \multirow[t]{2}{*}{ Recurrent concussion } & Yes & $2.08(1.28-3.36)^{*}$ & 0.003 \\
\hline & No & 1.0 & \\
\hline No. of symptoms & (1-unit increase) & $0.88(0.65-1.19)$ & 0.40 \\
\hline \multicolumn{4}{|l|}{ Symptom prevalence } \\
\hline \multirow[t]{2}{*}{ Posttraumatic amnesia } & Yes & $1.34(0.67-2.67)$ & 0.41 \\
\hline & No & 1.0 & \\
\hline \multirow[t]{2}{*}{ Retrograde amnesia } & Yes & $2.75(1.34-5.64)^{*}$ & 0.006 \\
\hline & No & 1.0 & \\
\hline \multirow[t]{2}{*}{ Difficulty concentrating } & Yes & $2.35(1.23-4.50)^{*}$ & 0.01 \\
\hline & No & 1.0 & \\
\hline \multirow[t]{2}{*}{ Dizziness } & Yes & $1.35(0.71-2.56)$ & 0.36 \\
\hline & No & 1.0 & \\
\hline \multirow[t]{2}{*}{ Excess irritability } & Yes & $0.97(0.52-1.82)$ & 0.93 \\
\hline & No & 1.0 & \\
\hline \multirow[t]{2}{*}{ Nausea/vomiting } & Yes & $1.19(0.69-2.07)$ & 0.53 \\
\hline & No & 1.0 & \\
\hline \multirow[t]{2}{*}{ Loss of balance } & Yes & $1.05(0.59-1.87)$ & 0.87 \\
\hline & No & 1.0 & \\
\hline \multirow[t]{2}{*}{ Visual disturbance } & Yes & $1.31(0.76-2.24)$ & 0.33 \\
\hline & No & 1.0 & \\
\hline \multirow[t]{2}{*}{ Sensitivity to light } & Yes & $1.97(1.09-3.57)^{\star}$ & 0.004 \\
\hline & No & 1.0 & \\
\hline \multirow[t]{2}{*}{ Sensitivity to noise } & Yes & $1.53(0.86-2.74)$ & 0.15 \\
\hline & No & 1.0 & \\
\hline \multirow[t]{2}{*}{ Insomnia } & Yes & $2.19(1.30-3.68)^{*}$ & 0.003 \\
\hline & No & 1.0 & \\
\hline \multirow[t]{2}{*}{ Excess drowsiness } & Yes & $1.56(0.88-2.77)$ & 0.12 \\
\hline & No & 1.0 & \\
\hline
\end{tabular}

* Statistically significant.

PCS definition of approximately greater than 4 weeks. We also found that the total number of symptoms was not associated with PCS. Although definitions of PCS specify a threshold for the number of symptoms that a concussed person must identify, ${ }^{2,3}$ our findings may suggest that the type of symptoms reported are more important than the quantity. As mentioned previously, in a study in which more than 500 physicians were surveyed, the majority of the physicians diagnosed PCS in patients with 1 symptom for a minimum of 4 weeks. ${ }^{42}$

However, it is important to note that other studies have found an association between concussion symptom inventory scores and PCS. Meehan et al. ${ }^{30}$ reported that among a host of possible signs and symptoms, only total score on a symptom inventory was associated with symptoms lasting more than 4 weeks. In a comprehensive systematic review of general traumatic brain injury, ${ }^{45}$ the total symptom severity score was associated with PCS in 4 of the 8 studies discussed. Although the ISP uses a 17-symptom checklist, it does not measure the severity of the symp- toms. Future research should continue to examine how the type, number, and severity of symptoms are associated with long-term outcomes associated with SRC.

Our findings contradict previous results in that several variables included in our models had null associations with PCS. For example, our findings did not detect an association between sex and PCS, whereas previous research has found an increased risk among females, ${ }^{28,50}$ although those studies were conducted in children/adolescents, not collegiate student-athletes. In addition, a meta-analysis of studies that examined individuals who sustained a traumatic brain injury found that only 6 of the 12 studies examined reported worse symptomatic outcomes for women. ${ }^{45}$ Previous research also identified LOC as a risk factor associated with PCS. ${ }^{26}$ McCrea et al. ${ }^{26}$ studied a sport-specific cohort and found a positive correlation between LOC and PCS; however, prolonged recovery was defined at only $>$ 7 days. ${ }^{26}$ A recent meta-analysis found LOC not to be associated with outcomes in only 2 of 8 studies, and 1 of the 2 positive studies was unblinded. ${ }^{45}$ All those studies 
were conducted in a general population, and most were in children and adolescents who presented to the emergency department.

Also, although 1 previous study identified helmeted versus unhelmeted status as a predictor of acute outcome after SRC, ${ }^{53}$ we did not find helmet status to be associated with PCS. Although most media attention surrounds collision sports such as football and hockey, contact level did not predict PCS in our cohort. Given the body of mixed findings in the literature, we recommend additional prospective research with large samples of concussed individuals to better identify the risk factors associated with PCS.

When interpreting the results of this study, the setting and context of a collegiate environment must be considered. The current NCAA guidelines mandate that clearance for a concussed student-athlete to return to athletic activity must be determined by a physician or physician designee. ${ }^{34}$ Furthermore, same-day return to play is not permitted..$^{34} \mathrm{~A}$ recent survey of coaches, sports medicine clinicians, and compliance administrators at 907 NCAA institutions reported that more than one-third of the respondents thought that concussion safety education among coaches and players could be improved. ${ }^{5}$ Another potential area of improvement is communication between team medical staff and academic advisors. In an academic setting, memory, concentration, and sleep are crucial for successful scholastic performance. Thus, in the collegiate population, the student-athlete may be hyperaware of small declines in concentration, memory, and sleep, leading to appropriately increased reporting of these specific symptoms. For example, the concentration, memory, and sleep of college student-athletes who are studying for an examination will need to be at a high level, or at least at their previous baseline level, or they will be aware of their suboptimal performance. Some studies have discussed guidelines for students returning to class after a concussion-including deadline extensions, rest periods, and accommodation for light or noise sensitivity-although such guidelines have been used mostly at the high school level and below.,36,49 One study evaluated 34 collegiate concussions among a greater cohort of 159 patients and found that recurrence or worsening of symptoms was seen in almost half (44.7\%) of the patients after a premature return to learning. ${ }^{9}$

\section{Limitations}

The NCAA ISP is a convenience sample of ATs from several NCAA member institutions and may not be generalizable to nonparticipating sports programs or other levels of competition (e.g., club sports, high school sports). Data were also collected from a previous time period that may not represent the current climate of SRC reporting. In addition, we did not provide a working definition of SRC, although the ATs were encouraged to follow the definition provided by the Consensus Statement on Concussion in Sport. ${ }^{27}$ This lack of a standard may have resulted in variation in SRC reporting. Other variables of interest, such as player position, NCAA divisional differences, and SRC outcomes, were outside the scope of this study. Factors such as learning disability, depression/anxiety, psychiatric illness, and family history have been shown to modify outcomes after concussion ${ }^{33}$; however, they could not be ac- counted for in our study, because the ISP is strictly for surveillance and is not a database of student-athletes' medical histories. Moreover, no baseline information was available; thus, predictive factors could be accounted for only in the postconcussive setting, and association only-not causation-could be concluded. Last, the accuracy of recurrent concussion status may have been variable, because this information can be difficult to obtain retrospectively from student-athletes.

\section{Future Directions}

The literature is replete with studies that aimed to delineate the precise factors that lead to PCS. However, many studies used heterogeneous cohorts, which makes their results difficult to apply. Nevertheless, it is essential to identify interventions that can assist concussed individuals in returning to their normal daily activities. In the case of a collegiate student-athlete, normal daily activities would include return to both sports and academics. Several pharmacological agents exist to treat unremitting symptoms such as headache, sleep disturbance, nausea, and dizziness. ${ }^{38,46}$ Conder and Conder ${ }^{10}$ described psychological rehabilitation efforts targeted at PCS symptom resolution, including cognitive behavioral therapy, relaxation training, biofeedback, and heart-rate-variability training. Although most of these interventions have had limited empirical support for efficacy in a sports environment, they have had success with similar injuries. Preliminary studies evaluated noninvasive brain stimulation, specifically repetitive transcranial magnetic stimulation over the prefrontal cortex, for the treatment of PCS. ${ }^{18}$ With respect to imaging, diffusion tensor imaging and detailed MRI data may provide new insight into those at risk for PCS. ${ }^{1,19}$ Last, education among athletes, coaches, and parents remains critical for improving PCS outcomes. Novel ways of disseminating concussion and PCS information may help diagnose and make school accommodations for those with persistent symptoms, especially in more rural populations. ${ }^{14}$ However, evaluation through prospective observational research and randomized controlled trials is important for gauging the effectiveness and efficacy of these interventions.

\section{Conclusions}

Our study ventured to examine factors associated with PCS at the collegiate level. The factors in our multivariate model that predicted the odds of PCS included recurrent concussion, retrograde amnesia, difficulty concentrating, light sensitivity, and insomnia. Sex, contact level, helmet status, and LOC were not associated with PCS. Our ability to identify the determinants of PCS may enable earlier preventative care aimed at decreasing morbidity. Further study is needed to continue improving our predictive ability and to employ early treatment strategies to prevent the development of PCS.

\section{References}

1. Albaugh MD, Orr C, Nickerson JP, Zweber C, Slauterbeck JR, Hipko S, et al: Postconcussion symptoms are associated with cerebral cortical thickness in healthy collegiate and preparatory school ice hockey players. J Pediatr 166:394-400, 400.e1, 2015 
2. American Psychiatric Association: Diagnostic and Statistical Manual of Mental Disorders, ed 4. Washington, DC: American Psychiatric Association, 2000

3. American Psychiatric Association: Diagnostic and Statistical Manual of Mental Disorders, ed 5. Washington, DC: American Psychiatric Association, 2013

4. Baker JG, Leddy JJ, Darling SR, Rieger BP, Mashtare TL, Sharma T, et al: Factors associated with problems for adolescents returning to the classroom after sport-related concussion. Clin Pediatr (Phila) 54:961-968, 2015

5. Baugh CM, Kroshus E, Daneshvar DH, Filali NA, Hiscox MJ, Glantz LH: Concussion management in United States college sports: compliance with National Collegiate Athletic Association concussion policy and areas for improvement. Am J Sports Med 43:47-56, 2015

6. Bazarian JJ, Atabaki S: Predicting postconcussion syndrome after minor traumatic brain injury. Acad Emerg Med 8:788795, 2001

7. Bazarian JJ, Wong T, Harris M, Leahey N, Mookerjee S, Dombovy M: Epidemiology and predictors of post-concussive syndrome after minor head injury in an emergency population. Brain Inj 13:173-189, 1999

8. Belanger HG, Barwick FH, Kip KE, Kretzmer T, Vanderploeg RD: Postconcussive symptom complaints and potentially malleable positive predictors. Clin Neuropsychol 27:343-355, 2013

9. Carson JD, Lawrence DW, Kraft SA, Garel A, Snow CL, Chatterjee A, et al: Premature return to play and return to learn after a sport-related concussion: physician's chart review. Can Fam Physician 60:e310, e312-e315, 2014

10. Conder R, Conder AA: Neuropsychological and psychological rehabilitation interventions in refractory sport-related post-concussive syndrome. Brain Inj 29:249-262, 2015

11. Daneshvar DH, Nowinski CJ, McKee AC, Cantu RC: The epidemiology of sport-related concussion. Clin Sports Med 30:1-17, vii, 2011

12. Ellis MJ, Ritchie LJ, Koltek M, Hosain S, Cordingley D, Chu $\mathrm{S}$, et al: Psychiatric outcomes after pediatric sports-related concussion. J Neurosurg Pediatr 16:709-718, 2015

13. Franke LM, Czarnota JN, Ketchum JM, Walker WC: Factor analysis of persistent postconcussive symptoms within a military sample with blast exposure. J Head Trauma Rehabil 30:E34-E46, 2015

14. Glang AE, Koester MC, Chesnutt JC, Gioia GA, McAvoy K, Marshall S, et al: The effectiveness of a web-based resource in improving postconcussion management in high schools. $\mathbf{J}$ Adolesc Health 56:91-97, 2015

15. Hou R, Moss-Morris R, Peveler R, Mogg K, Bradley BP, Belli A: When a minor head injury results in enduring symptoms: a prospective investigation of risk factors for postconcussional syndrome after mild traumatic brain injury. J Neurol Neurosurg Psychiatry 83:217-223, 2012

16. Kerr ZY, Dompier TP, Snook EM, Marshall SW, Klossner D, Hainline B, et al: National collegiate athletic association injury surveillance system: review of methods for 2004-2005 through 2013-2014 data collection. J Athl Train 49:552560, 2014

17. King NS: Emotional, neuropsychological, and organic factors: their use in the prediction of persisting postconcussion symptoms after moderate and mild head injuries. J Neurol Neurosurg Psychiatry 61:75-81, 1996

18. Koski L, Kolivakis T, Yu C, Chen JK, Delaney S, Ptito A: Noninvasive brain stimulation for persistent postconcussion symptoms in mild traumatic brain injury. J Neurotrauma 32:38-44, 2015

19. Lange RT, Panenka WJ, Shewchuk JR, Heran MK, Brubacher JR, Bioux S, et al: Diffusion tensor imaging findings and postconcussion symptom reporting six weeks following mild traumatic brain injury. Arch Clin Neuropsychol 30:7-25, 2015
20. Langlois JA, Rutland-Brown W, Wald MM: The epidemiology and impact of traumatic brain injury: a brief overview. J Head Trauma Rehabil 21:375-378, 2006

21. Lau BC, Collins MW, Lovell MR: Cutoff scores in neurocognitive testing and symptom clusters that predict protracted recovery from concussions in high school athletes. Neurosurgery 70:371-379, 2012

22. Llewellyn T, Burdette GT, Joyner AB, Buckley TA: Concussion reporting rates at the conclusion of an intercollegiate athletic career. Clin J Sport Med 24:76-79, 2014

23. Luoto TM, Iverson GL, Losoi H, Wäljas M, Tenovuo O, Kataja A, et al: Clinical correlates of retrograde amnesia in mild traumatic brain injury. Brain Inj 29:565-572, 2015

24. Makdissi M, Cantu RC, Johnston KM, McCrory P, Meeuwisse WH: The difficult concussion patient: what is the best approach to investigation and management of persistent $(>10$ days) postconcussive symptoms? Br J Sports Med 47:308313, 2013

25. McCauley SR, Wilde EA, Miller ER, Frisby ML, Garza HM, Varghese R, et al: Preinjury resilience and mood as predictors of early outcome following mild traumatic brain injury. $\mathbf{J}$ Neurotrauma 30:642-652, 2013

26. McCrea M, Guskiewicz K, Randolph C, Barr WB, Hammeke TA, Marshall SW, et al: Incidence, clinical course, and predictors of prolonged recovery time following sport-related concussion in high school and college athletes. J Int Neuropsychol Soc 19:22-33, 2013

27. McCrory P, Meeuwisse WH, Aubry M, Cantu B, Dvořák J, Echemendia RJ, et al: Consensus statement on concussion in sport: the 4th International Conference on Concussion in Sport held in Zurich, November 2012. Br J Sports Med 47:250-258, 2013

28. McNally KA, Bangert B, Dietrich A, Nuss K, Rusin J, Wright $\mathrm{M}$, et al: Injury versus noninjury factors as predictors of postconcussive symptoms following mild traumatic brain injury in children. Neuropsychology 27:1-12, 2013

29. Meehan WP III, d'Hemecourt P, Comstock RD: High school concussions in the 2008-2009 academic year: mechanism, symptoms, and management. Am J Sports Med 38:24052409,2010

30. Meehan WP III, Mannix R, Monuteaux MC, Stein CJ, Bachur RG: Early symptom burden predicts recovery after sport-related concussion. Neurology 83:2204-2210, 2014

31. Meehan WP III, Mannix RC, Stracciolini A, Elbin RJ, Collins MW: Symptom severity predicts prolonged recovery after sport-related concussion, but age and amnesia do not. J Pediatr 163:721-725, 2013

32. Morgan CD, Zuckerman SL, King LE, Beaird SE, Sills AK, Solomon GS: Post-concussion syndrome (PCS) in a youth population: defining the diagnostic value and cost-utility of brain imaging. Childs Nerv Syst 31:2305-2309, 2015

33. Morgan CD, Zuckerman SL, Lee YM, King L, Beaird S, Sills AK, et al: Predictors of postconcussion syndrome after sports-related concussion in young athletes: a matched casecontrol study. J Neurosurg Pediatr 15:589-598, 2015

34. National Collegiate Athletic Association: 2013-14 NCAA Sports Medicine Handbook. Indianapolis, IN: NCAA, 2013

35. Olsson KA, Lloyd OT, Lebrocque RM, McKinlay L, Anderson VA, Kenardy JA: Predictors of child post-concussion symptoms at 6 and 18 months following mild traumatic brain injury. Brain Inj 27:145-157, 2013

36. Olympia RP, Ritter JT, Brady J, Bramley H: Return to learning after a concussion and compliance with recommendations for cognitive rest. Clin J Sport Med [epub ahead of print], 2015

37. Ouellet J, Rouleau I, Labrecque R, Bernier G, Scherzer PB: Two routes to losing one's past life: a brain trauma, an emotional trauma. Behav Neurol 20:27-38, 2008

38. Petraglia AL, Maroon JC, Bailes JE: From the field of play to 
the field of combat: a review of the pharmacological management of concussion. Neurosurgery 70:1520-1533, 2012

39. Ponsford J, Cameron P, Fitzgerald M, Grant M, MikockaWalus A, Schönberger M: Predictors of postconcussive symptoms 3 months after mild traumatic brain injury. Neuropsychology 26:304-313, 2012

40. Reuben A, Sampson P, Harris AR, Williams H, Yates P: Postconcussion syndrome (PCS) in the emergency department: predicting and pre-empting persistent symptoms following a mild traumatic brain injury. Emerg Med J 31:7277, 2014

41. Rice SG: Medical conditions affecting sports participation. Pediatrics 121:841-848, 2008

42. Rose SC, Fischer AN, Heyer GL: How long is too long? The lack of consensus regarding the post-concussion syndrome diagnosis. Brain Inj 29:798-803, 2015

43. Ruff RM, Camenzuli L, Mueller J: Miserable minority: emotional risk factors that influence the outcome of a mild traumatic brain injury. Brain Inj 10:551-565, 1996

44. Shehata N, Wiley JP, Richea S, Benson BW, Duits L, Meeuwisse WH: Sport concussion assessment tool: baseline values for varsity collision sport athletes. Br J Sports Med 43:730734, 2009

45. Silverberg ND, Gardner AJ, Brubacher JR, Panenka WJ, Li JJ, Iverson GL: Systematic review of multivariable prognostic models for mild traumatic brain injury. J Neurotrauma 32:517-526, 2015

46. Solomon GS, Sills AK: Pharmacologic treatment of sport-related concussion: a review. J Surg Orthop Adv 22:193-197, 2013

47. Tator $\mathrm{CH}$, Davis $\mathrm{H}$ : The postconcussion syndrome in sports and recreation: clinical features and demography in 138 athletes. Neurosurgery 75 (Suppl 4):S106-S112, 2014

48. Wasserman EB, Kerr ZY, Zuckerman SL, Covassin T: Epidemiology of sports-related concussions in National Collegiate Athletic Association athletes from 2009-2010 to 2013-2014: symptom prevalence, symptom resolution time, and returnto-play time. Am J Sports Med 44:226-233, 2016

49. Wing R, Amanullah S, Jacobs E, Clark MA, Merritt C: Heads up: communication is key in school nurses' preparedness for facilitating "return to learn" following concussion. Clin Pediatr (Phila) 55:228-235, 2015
50. Yeates KO, Taylor HG, Rusin J, Bangert B, Dietrich A, Nuss $\mathrm{K}$, et al: Premorbid child and family functioning as predictors of post-concussive symptoms in children with mild traumatic brain injuries. Int J Dev Neurosci 30:231-237, 2012

51. Zemek RL, Farion KJ, Sampson M, McGahern C: Prognosticators of persistent symptoms following pediatric concussion: a systematic review. JAMA Pediatr 167:259-265, 2013

52. Zuckerman SL, Kerr ZY, Yengo-Kahn A, Wasserman E, Covassin T, Solomon GS: Epidemiology of sports-related concussion in NCAA athletes from 2009-2010 to 2013-2014: incidence, recurrence, and mechanisms. Am J Sports Med 43:2654-2662, 2015

53. Zuckerman SL, Lee YM, Odom MJ, Forbes JA, Solomon GS, Sills AK: Sports-related concussion in helmeted vs. unhelmeted athletes: who fares worse? Int J Sports Med 36:419-425, 2015

\section{Disclosures}

Dr. Solomon reports being a consultant for the Tennessee Titans, Nashville Predators, and ImPACT. Dr. Sills reports being a non-compensated consultant to several collegiate athletic teams including Vanderbilt University.

\section{Author Contributions}

Conception and design: Zuckerman, Kerr. Acquisition of data: Kerr. Analysis and interpretation of data: all authors. Drafting the article: Zuckerman, Yengo-Kahn. Critically revising the article: all authors. Reviewed submitted version of manuscript: Zuckerman, Buckley, Solomon, Sills, Kerr. Approved the final version of the manuscript on behalf of all authors: Zuckerman. Statistical analysis: Kerr. Administrative/technical/material support: Solomon, Kerr. Study supervision: Zuckerman, Solomon, Kerr.

\section{Correspondence}

Scott L. Zuckerman, Department of Neurological Surgery, Vanderbilt University Medical Center, 1211 Medical Center Dr., T-4224 Medical Center North, Nashville, TN 37232-2380. email: scott.zuckerman@vanderbilt.edu. 